
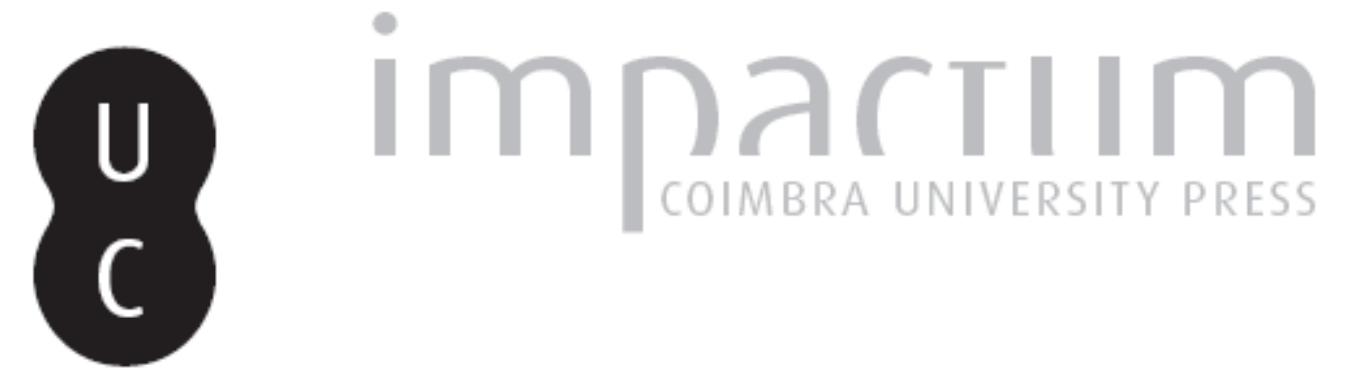

\author{
Arquitetura e espiritualidade dos Franciscanos nos primórdios em Portugal \\ Autor(es): $\quad$ Macedo, Francisco Pato de \\ Publicado por: Imprensa da Universidade de Coimbra \\ URL \\ persistente: URI:http://hdl.handle.net/10316.2/44969 \\ DOI: $\quad$ DOl:https://doi.org/10.14195/0870-8584_12_6 \\ Accessed : $\quad$ 26-Apr-2023 12:11:36
}

A navegação consulta e descarregamento dos títulos inseridos nas Bibliotecas Digitais UC Digitalis, UC Pombalina e UC Impactum, pressupõem a aceitação plena e sem reservas dos Termos e Condições de Uso destas Bibliotecas Digitais, disponíveis em https://digitalis.uc.pt/pt-pt/termos.

Conforme exposto nos referidos Termos e Condições de Uso, o descarregamento de títulos de acesso restrito requer uma licença válida de autorização devendo o utilizador aceder ao(s) documento(s) a partir de um endereço de IP da instituição detentora da supramencionada licença.

Ao utilizador é apenas permitido o descarregamento para uso pessoal, pelo que o emprego do(s) título(s) descarregado(s) para outro fim, designadamente comercial, carece de autorização do respetivo autor ou editor da obra.

Na medida em que todas as obras da UC Digitalis se encontram protegidas pelo Código do Direito de Autor e Direitos Conexos e demais legislação aplicável, toda a cópia, parcial ou total, deste documento, nos casos em que é legalmente admitida, deverá conter ou fazer-se acompanhar por este aviso.

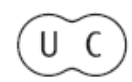




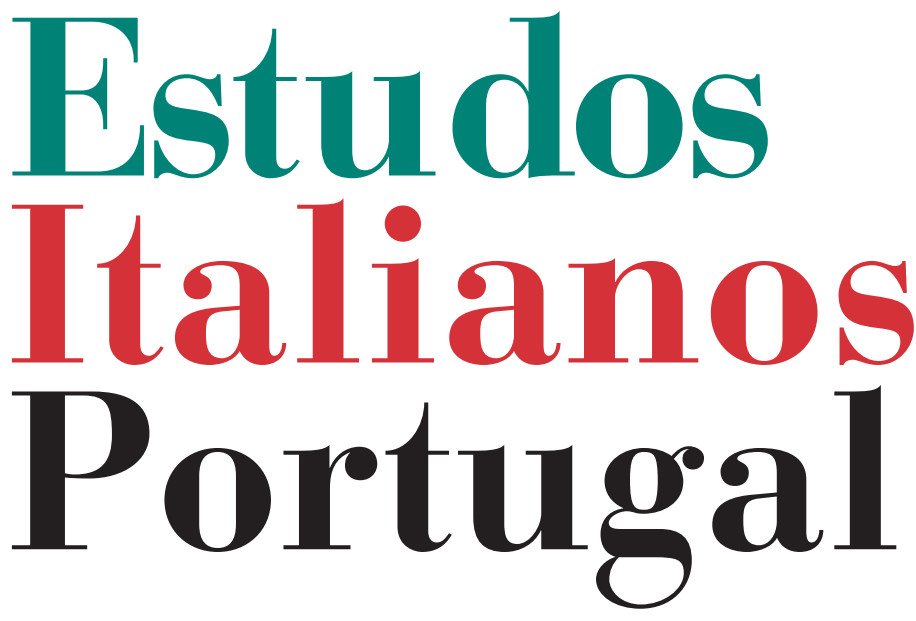

Instituto

Italiano

de Cultura

de Lisboa

Nova Série

No 12

2017 


\section{ARQUITETURA E ESPIRITUALIDADE \\ DOS FRANCISCANOS \\ NOS PRIMÓRDIOS EM PORTUGAL}

Francisco Pato de Macedo*

A ARQUITETURA MEDIEVAL dos mendicantes em território português continua a aguardar um estudo abrangente e sólido. Esta lacuna apenas pode ser compensada com o recurso aos dados, embora parcos e esparsos, já coletados.

Neste artigo panorâmico será esquissado um elenco das problemáticas atinentes ao estudo da arquitetura dos Frades Menores, nos séculos XIII e XIV. Tanto as que se relacionam com a implantação dos seus conventos no reino mais ocidental da Península, quanto as referentes à sua adequação ao ideal espiritual e ao normativo construtivo emanado dos Concílios da Ordem, bem como as que dizem respeito á funcionalidade das suas igrejas em conexão com a pastoral e a liturgia. Será ainda esboçada uma caraterização dos templos de Franciscanos edificados nesses tempos primordiais.

A circunstância em que se processou a fundação de cada convento; as questóes da topografia de assentamento em ligação com o tecido urbano coevo; os intervenientes implicados na fundação de cada convento e o reflexo destes na construção e na finalidade das igrejas; as potencialidades humanas, económicas, materiais e técnicas; o enquadramento sociocultural e político; os sistemas construtivos e o processo de construção e sua cronologia são um conjunto amplo de

* Professor aposentado da Faculdade de Letras da Universidade de Coimbra. Membro do CEAACP, Centro de Estudos de Arqueologia, Artes e Ciências do Património. Doutorado em História da Arte pela UC. fracedo@gmail.com 
questôes magnas a ter em conta ao abordar a arquitetura dos Franciscanos. No entanto, relativamente aos primeiros tempos da Ordem, as respostas a muitas destas perguntas são geralmente vagas ou mesmo impossíveis de obter. Quer por insuficiência da documentação escrita, quer pela carência de intervenções arqueológicas sistemáticas no remanescente de conventos conservados, quer ainda pela inexistência de estudos aprofundados e exaustivos sobre iconografia antiga.

$\mathrm{O}$ ideal de itinerância, que fez os seguidores de Francisco de Assis espalharem-se pelo mundo, trouxe-os bem cedo à Península Ibérica. Portugal acolheu-os completam-se agora precisamente oitocentos anos. Contudo, o processo da sua implantação em território português, tal como, aliás, na generalidade do solo peninsular ${ }^{1}$, permanece envolto em brumas que dificultam o estabelecimento do seu itinerário, tanto cronológico quanto geográfico (Cuadrado Sanchez 1991: 25). Emerge, contudo, o desiderato de cobrir a generalidade do território português, exteriorizado numa estratégia pautada pelo objetivo de cobrir a zona setentrional do reino, mas também de demandar a região meridional, onde o processo de 'reconquista' ainda se encontrava por concluir. A concretização deste ambicioso projeto compeliu à fundação de um número elevado de conventos, num processo que, em alguns casos, motivou discórdias quer com o clero secular quer com outras ordens religiosas já implantadas no terreno, de que resultaram conflitos abertos.

O espaço geográfico do reino onde tiveram lugar, no decurso do século XIII, as fundações mais importantes, situa-se na Estremadura e no Ribatejo, regióes ricas e com importantes centros urbanos, como Lisboa e Santarém, e com povoações situadas na rede primária de comunicações, tais como Alenquer e Leiria. A região a norte de Coimbra, cidade cedo demandada pelos Franciscanos devido à sua importância, é

\footnotetext{
${ }^{1}$ Garcia Oro (1991: 25) adverte para os escolhos que irá encontrar quem se ocupe do processo cronológico e geográfico da implantação dos Franciscanos.
} 
uma zona de povoamento denso, particularmente no norte litoral, onde existem povoaçôes em franco crescimento, caso da cidade do Porto, que rivalizava, juntamente com Guimarães, com o protagonismo simbólico de Braga. No norte interior, a diocesana cidade da Guarda e a densamente povoada, mas pouco próspera, Covilhã constituíram polos de atração, enquanto Bragança tem de ser olhada em relação com o Caminho de Santiago. A zona meridional propiciava um confronto religioso com o mundo muçulmano, que Francisco de Assis $^{2}$ sempre havia desejado. Nesse sentido, os Franciscanos chegaram ao Alentejo, a partir de meados do século XIII, a Évora, Beja e Estremoz ou à raiana Portalegre e, já no século XIV, alcançaram no Algarve as cidades de Tavira e Loulé.

Os grandes centros urbanos revelavam-se o terreno propício para o tipo de apostolado dos Franciscanos, para além de lhes garantirem a habitação e a subsistência. Por conseguinte, foi nas cidades que quase exclusivamente se fixaram, de tal modo que estas se tornaram o seu ambiente quase natural. A história urbana europeia a partir do século XIII não pode ser feita sem ter em conta a presença dos mendicantes, pois as cidades passaram a ser tanto mais fortes demograficamente e florescentes do ponto de vista económico, quanto maiores fossem as comunidades de mendicantes que as habitavam (Pellegini 1990: 30).

O estudo dos monumentos mendicantes isolados, sem ligação ao tecido urbano coevo, é hoje considerado anticientífico $^{3}$. Em França, Jacques Le Goff promoveu, de modo pioneiro, nos anos 70 do século XX, a execução de um trabalho coletivo sobre a documentação mendicante, tendo em vista o estudo da história urbana da França medieval (Le Goff

${ }^{2}$ Francisco de Assis fez várias tentativas de levar o Evangelho a terras muçulmanas, mas em 1214 não chegou a ir a Marrocos e em 1219 na sua missão ao Egito não logrou converter o Sultão.

${ }^{3}$ Raspi Serra (1990: 14) defende a necessidade de promover uma análise interdisciplinar do significado do movimento mendicante no âmbito urbano e social. 
1968: 335-352). Entre nós, as fundaçōes dos Frades Menores no século XIII mereceram a José Mattoso um estudo do seu enquadramento social e económico ${ }^{4}$. Este autor tomou por base o rol dos tabeliães de 1290, mandado executar por D. Dinis, fundamental para calcular a população urbana em termos relativos, e concluiu que os franciscanos procuraram para se fixar os centros urbanos de maior dimensão. $\mathrm{Na}$ realidade, todas as cidades com 5 ou mais tabeliães viram estabelecerem-se conventos franciscanos (Guarda, Covilhã, Coimbra e Évora com 5 tabeliães, Bragança 6, Santarém 15 e Lisboa 21). Quanto ao Porto e Braga, urbes também então de significativa importância, não surgem mencionadas no rol de 1290 , devido a serem senhorios eclesiásticos e não ser o rei a designar os tabeliães. Contudo, os Frades Menores estabeleceram-se no Porto, embora em Braga apenas tenham fundado um hospício. Quanto a centros com quatro ou três tabeliães, não se instalaram em todos, mas vão estar presentes em Leiria, Alenquer e Estremoz.

Foi, por conseguinte, num quadro de renovação cultural e civil, de afirmação de novas instituiçõoes e de desenvolvimento intelectual e tecnológico, que os Frades Menores se tornaram os pregadores por excelência do povo humilde, em particular na periferia das cidades, encabeçando a direção espiritual das massas e orientando a piedade. Em breve, contudo, iriam conquistar também os restantes estratos da sociedade, consolidar o seu poder e aumentar os réditos auferidos, o que se irá refletir na arquitetura dos seus conventos.

No decurso do processo do assentamento dos Franciscanos em Portugal, seis dos conventos então fundados começaram por se estabelecer fora das cidades junto às muralhas e portas ou na proximidade de capelas, ermidas ou fontes já pré-existentes, em edifícios de grande precariedade. Só num segundo

\footnotetext{
${ }^{4}$ Mattoso (1985: 335-35) propõe uma análise estrutural do tecido urbano onde ocorreram as fundações de conventos franciscanos e uma análise conjuntural da provável relação das fundações com a evolução coeva do mundo urbano.
} 
momento, por motivaçôes de cariz apostólico, ausência de condições do primitivo assentamento, dificuldade de acesso aos centros urbanos e pressão das populações, se acercaram do perímetro urbano e aí procederam á construção de conventos, na maioria das vezes em local definitivo, embora se possam documentar casos de mais do que uma mudança. Esta deslocação para um sítio considerado mais adequado em termos estratégicos complexifica a questão de saber quando ocorre verdadeiramente a fundação de um convento. Importa determinar se esta corresponde ao momento em que a Ordem recebe autorização para se implantar num determinado sítio ou, pelo contrário, se apenas pode ser balizada no início da construção de instalações conventuais com carácter mais definitivo. Esta ambiguidade obsta ao estabelecimento de uma cronologia segura da implantação da Ordem, com claros reflexos na escrita da história da arquitetura dos seus conventos.

A cartografia do assentamento torna-se ainda mais complexa nos casos em que houve uma instabilitas loci mais prolongada, visto que o percurso da passagem de instalações provisórias ao convento definitivo se encontra, na maioria dos casos, escassamente documentado. Regra geral essa transferência apenas é dada a conhecer pelos cronistas em narrativas muito tardias relativamente aos factos e feitas numa linguagem estereotipada. Efetivamente, os relatos das crónicas surgem ajustados a um modelo de glorificação dos primitivos ideais franciscanos de despojamento e pobreza, que é quase invariavelmente repetido em cada fundação. Os aspetos essenciais dessa matriz são a exaltação doutrinária de um apostolado, eficaz e cumpridor da sua missão, executada a partir de lugares ermos e sem a necessidade de uma vida monástica ou conventual, assim como a obediência dos primeiros edifícios às regras da pobreza.

O louvor deste modo de evangelização encontra expressão nas seguintes fórmulas: "viver recolhido sem faltar ao bem comum das almas" ou " procurar remédio das almas sem 
dispêndio das obrigaçôes do coro". A submissão da arquitetura dos primeiros assentamentos às normas da pobreza é constantemente ressaltada em expressōes como: "conventos pobres, piquenos e humildes", "Os edificios erão terreiros \& pobres" ou "pela traça e medidas da santa pobreza" ou ainda "ordenarem a casa pela plãta que então se praticava, piquena, $\&$ muito pobre".

A humildade, a pequenez e a pobreza, expostas muitas vezes pelos cronistas, através da expressão "pouquidades", contrapõe-se ao que denominam "grandezas". Sendo estas, no respeitante aos edifícios conventuais, quase invariavelmente traduzidas por expressões como "grandiosas machinas" ou "sumptuosa fabrica", lugares-comuns usados em relação a edifícios que, pelas suas caraterísticas majestosas, subvertem o espírito inicial da Ordem.

A construção de edifícios de maior dimensão e imponência deveu-se à necessidade de espaços eclesiásticos com a amplidão necessária a poder acolher um público cada vez mais numeroso, mas também aos desígnios dos promotores. Na realidade, a edificação destas "grandiosas machinas", por parte de ordens de pobreza, só logrou concretizar-se graças ao patronato e é a este que cabe por inteiro a responsabilidade pela imponência de alguns dos conventos mendicantes. $\mathrm{O}$ mecenato exercido de modo individual e direto ou partilhado e indireto fundamenta-se em larga medida no desígnio de acrescentar a função cemiterial ou sepulcral, ao relevante destino pastoral das igrejas conventuais. O culto dos defuntos e o exercício da pregação não são concebíveis sem um certo fausto e o recurso à imagem. Coube aos mecenas a promoção de programas de enobrecimento dos espaços eclesiásticos, responsáveis por reverter o primitivo despojamento das igrejas e por as dotar de um mobiliário litúrgico considerado apropriado.

$O$ patronato de que foram beneficiários os Franciscanos liga-se com a sua reconhecida competência de servidores pontifícios e a sua relevante ação pastoral na pregação do despo- 
jamento e do ascetismo, que atraiu a devoção dos ricos com a consciência pesada pela opulência do seu tipo de vida e que, na hora da morte, os procuravam como intercessores, o que concluiria por fazer deles os grandes "especialistas" da morte. $\mathrm{Na}$ atração exercida junto de promotores pesaram também razōes de natureza política e social (Garcia Oro 2005: 201209), decorrentes da destacada posição usufruída pelos Frades Menores junto da corte, como confessores e conselheiros de reis e rainhas.

A quase generalidade dos conventos construídos entre nós, no tempo em análise, gozou, em algum momento da sua edificação, de patrocínio régio, essencialmente da parte de D. Afonso III e de D. Dinis e D. Isabel de Aragão, para além de contributos relevantes de outros membros da família real, da nobreza ou da burguesia desejosos de obterem a salvação eterna, mas também magnificência pessoal.

Quando se procura os conventos da Ordem dos Frades Menores fundados em Portugal, nos séculos XIII e XIV, localizados em espaço urbano ou periurbano, essencialmente na zona central e meridional do país, depara-se com um cenário de ausência, degradação, ampliação ou reconversão, que não permite sequer lograr obter uma resposta para o modo de ordenação do programa conventual. Subsistem praticamente só as igrejas e mesmo estas, quando não são monumentos desaparecidos, encontram-se, transformadas, degradadas, profanadas, reconvertidas ou 'restauradas'. No entanto, uma análise do remanescente e de fontes diversificadas permite afirmar que os Frades Menores foram responsáveis pela construção de edifícios eclesiásticos marcados por uma certa afinidade.

A identidade patente na arquitetura dos Frades Menores é a seu modo um reflexo da uniformidade que caracteriza a Ordem e se baseia em grandes princípios. Desde logo, no afeto fraternal entre os seus membros sem distinção de hierarquias. Depois, numa unidade de ação, pautada pelo exercício de tare- 
fas cumpridas por todos, com o mesmo espírito de abnegação e espontaneidade. Esta analogia foi extensiva aos religiosos de todos os países, porque cada convento, onde quer que estivesse, tinha como princípio o cuidado dos pobres e o acolhimento de todos os desafortunados. Para essa afinidade contribuiu também a adoção da liturgia da cúria romana, que propiciava uma integração mais fácil, em particular dos viandantes, que estas casas estavam sempre prontas a acolher. Acresce ainda uma uniformidade jurídica, para a qual contribuía a reunião anual de um Capítulo Geral da Ordem, fator fundamental à manutenção do equilíbrio com a unidade ideal, expressa numa Regra pouco extensa e de carácter prático.

Para a homogeneização da tipologia e dos programas das casas religiosas da Ordem contribuiu também a persistente importância das cláusulas conciliares, em particular as do Capítulo Geral dos Frades Menores, celebrado em Narbona em 1260, redigidas a instâncias de São Boaventura. A relevância que estas normas tiveram pode avaliar-se pelas sucessivas confirmações que receberam em capítulos gerais subsequentes, até cerca de 1500 , embora esta reafirmação permita também conjeturar ter havido dificuldade em fazê-las cumprir. Por conseguinte, o alcance destas medidas só pode ser verdadeiramente aferido, através da análise do seu impacto no tecido edificado de cada convento.

As igrejas de menoritas, construídas em Portugal nos séculos XIII e XIV, obedeceram, de um modo geral, aos preceitos de despojamento emanados do Capítulo Geral de Narbona. De facto, não se depara nelas com o supérfluo que, segundo estas constituições, está em contraposição direta com a pobreza ("Cum autem curiositas et superfluitas directe obviet paupertati” $)^{5}$. Não comportam também excessos decorativos ou dimensionais e obedecem ao preceito de não serem abobadadas, à exceção da capela-mor ("Ecclesiae autem nullo

${ }^{5}$ Braunfels (1975: 329-330) transcreve o texto latino das cláusulas capitulares, XIV Estatutos de los Franciscanos (1260, Fragmentos), bem como a tradução castelhana. 
mod fiant testudinatae excepta maiori capella”). Não possuem campanários em forma de torre ("Campanile ecclesiae ad modum turris de cetero nusquam fiat"). Para além de estarmos persuadidos, embora tal já não possa ser confirmado, de que também foi religiosamente obedecido o preceito de só permitir vitrais historiados ou com imagens, na janela principal atrás do altar-mor, lugar onde era dado consentimento para representar imagens do Crucifixo, da Virgem Maria, de São João, de São Francisco e de Santo António ("item fenestrae vitreae istoriatae vel picturatae de cetero nusquam fiant, excepto quod in principali vitrea, post maius altare chori, haberi possint imagines Crucifixi, beatae Virginis, beati Johannis, beati Francisci et beati Antonii tantum").

Vastas, de grande sobriedade e profusamente iluminadas, as igrejas dos Franciscanos, amplamente abertas a laicos, devem possibilitar ver claramente o desenrolar das cerimónias litúrgicas, ouvir distintamente o sermão e permitir que nelas seja até possível a leitura de um livro. Consagradas à celebração, à oração e à pregação, mas também a servir de locis sepulcralis, o que tem como consequência que uma parte do seu espaço, junto ao coro ou ao longo das paredes das naves, seja cedido aos laicos mais influentes ou magnânimos para os seus enterramentos privilegiados.

Os Franciscanos construíram, nos primórdios da Ordem no nosso país, templos de grande identidade, canonicamente orientados, de cabeceira com abside única ou de três ou cinco capelas, em qualquer dos casos sempre com cobertura abobadada, com ou sem transepto e de duas tipologias planimétricas, nave única ou três naves, de média dimensão, geralmente cinco tramos, e invariavelmente com cobertura em armação lígnea. A unidade do espaço interno contribuía para fazer sobressair o despojamento e acentuar a clareza formal e o carácter diáfano. No caso das igrejas de três naves, a concretização de espaços internos unitários obteve-se através da supressão de todas as divisórias, do adelgaçamento dos 


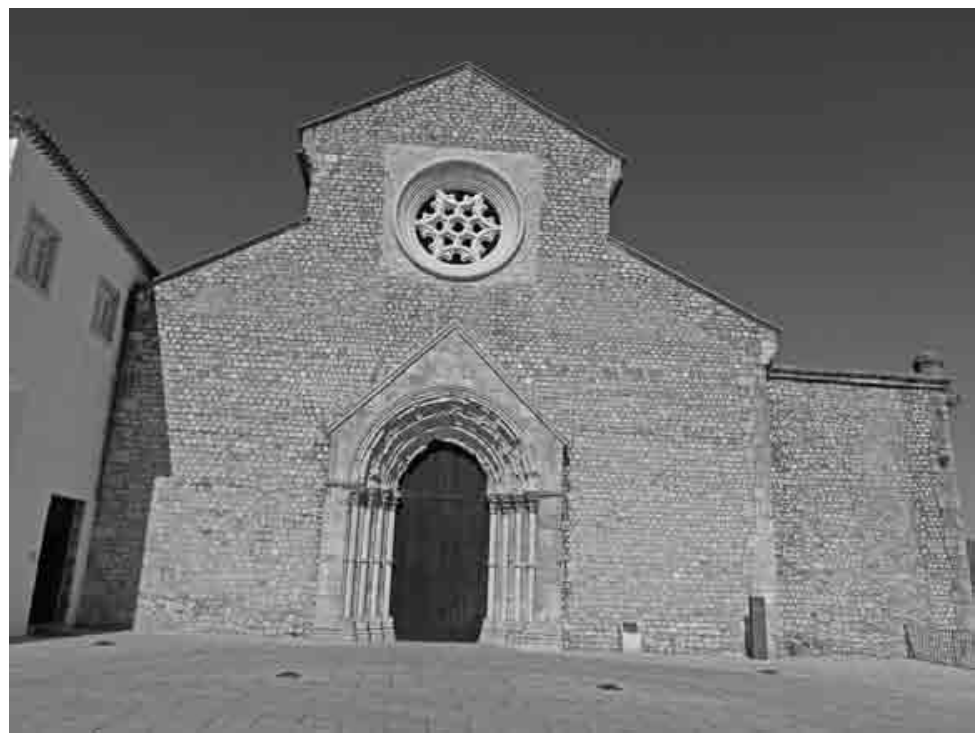

Fig. 1 Santarém. Igreja de São Francisco. Vista atual da fachada principal.

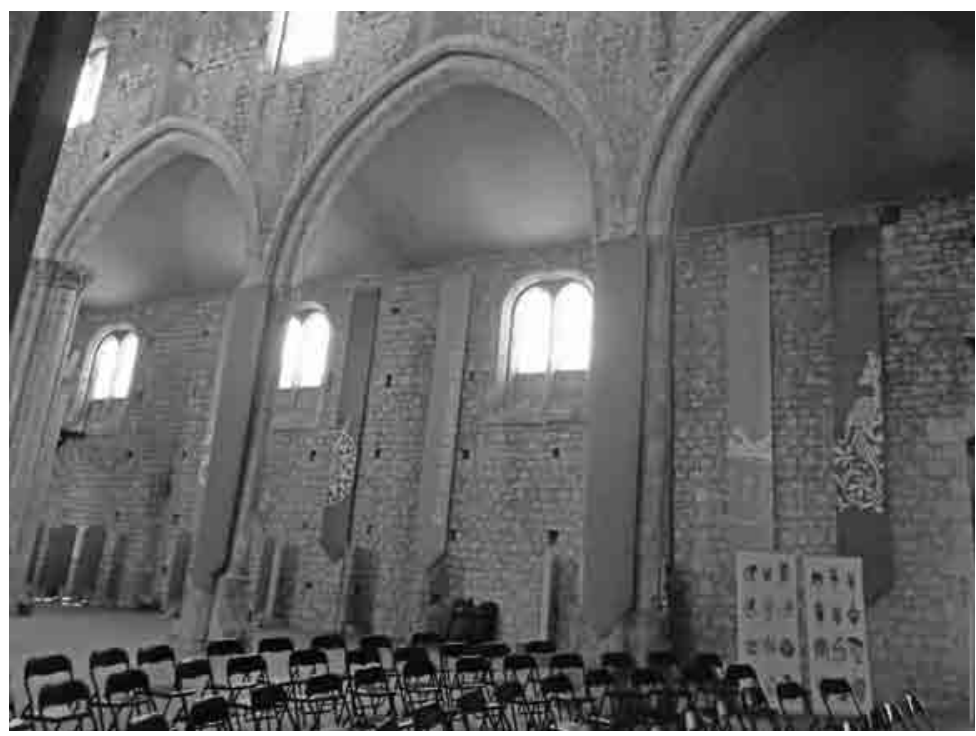

Fig. 2 Santarém. Igreja de São Francisco. Interior atual. 
pilares e da maior amplidão das arcadas, bem como por meio de uma iluminação emanada das janelas do clerestório e de rosáceas.

Esta tipologia, embora maioritária, pode apenas ser deduzida a partir de uma pequeno número de igrejas remanescentes do período em que decorreu a implantação da Ordem. Os conventos de São Francisco de Lisboa, Coimbra, Lamego, Beja e Guarda são hoje 'monumentos desaparecidos' e a arquitetura das suas igrejas é apenas dada a conhecer em fontes documentais ou iconográficas raras e esparsas. As igrejas dos conventos de Bragança, Guimarães, Covilhã, Leiria, Alenquer, Portalegre e Évora encontram-se hoje grandemente transformadas. Por conseguinte, tem sido às igrejas dos conventos de São Francisco de Santarém, do Porto e de Estremoz, as que melhor se conservam, que a historiografia tem recorrido para obter uma caraterização tipológica. Contudo, uma história da arquitetura medieval de Franciscanos tem de ser feita através dos edifícios que se conservam mas não pode prescindir de todos os que desapareceram ou foram transformados. Só após uma análise monográfica sistemática do que foi edificado, será possível definir as tipologias das igrejas e das restantes dependências conventuais, determinar modelos e ressaltar originalidades.

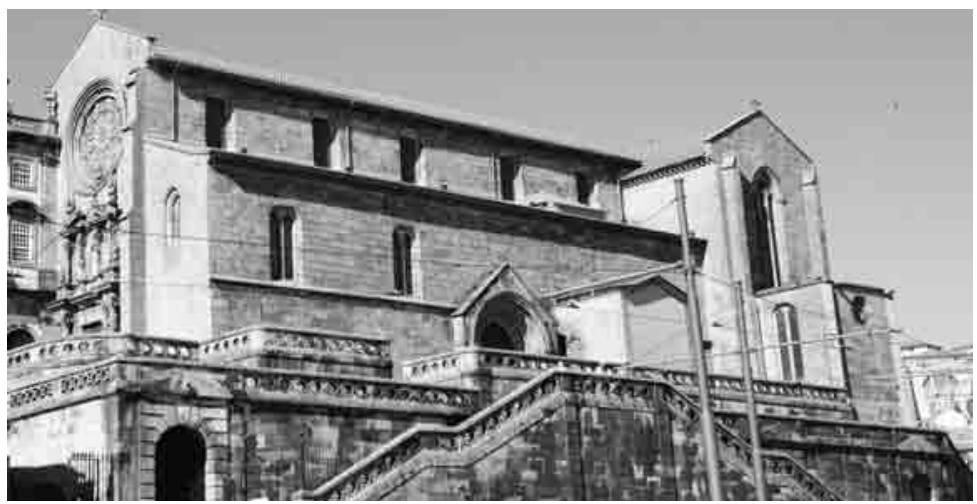

Fig. 3 Porto. Igreja de São Francisco. Vista exterior sudoeste. 


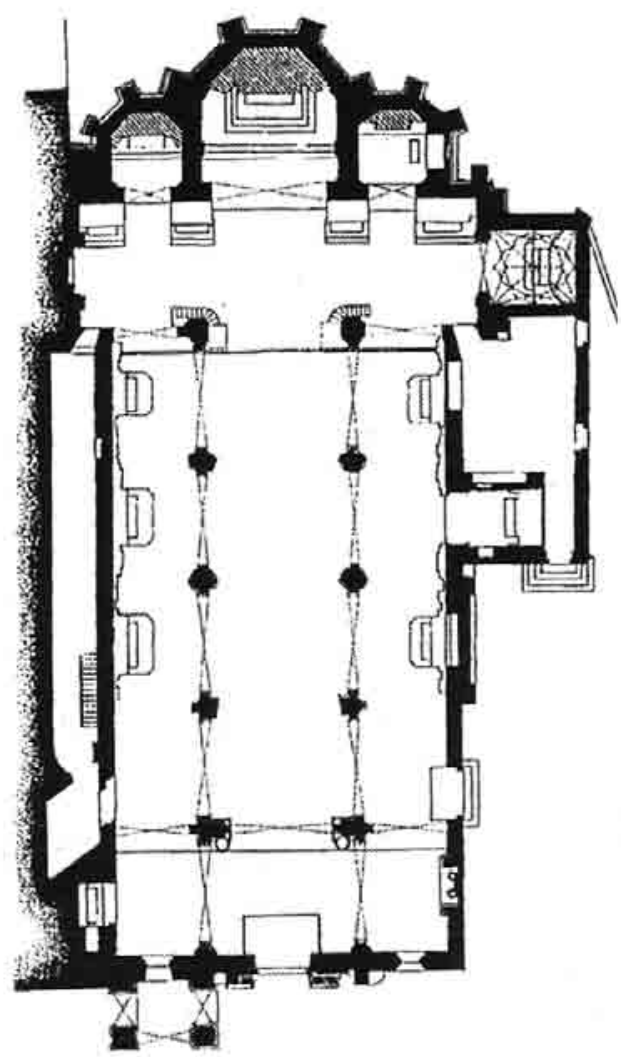

Fig. 4 Porto. Igreja de São Francisco. Planta atual.

Não obstante a inexistência de uma matriz arquitetónica de adjetivação franciscana, pode-se afirmar que os Frades Menores foram responsáveis por uma arquitetura de grande identidade, funcional e económica, de traça genericamente anónima, bem integrada na tradição construtiva local, que influenciou e de que recebeu influências. $\mathrm{O}$ tipo de construção ensaiado nos primeiros conventos menoritas, apesar de despojado e de não assentar em pressupostos conceptuais estéticos, forneceu um contributo à arquitetura religiosa que merece ser destacado. 
O patrocínio régio e a liturgia funerária foram responsáveis pela alteração progressiva da uniformidade arquitetónica, ao fazerem pender o binómio austeridade/ esplendor em favor deste último, com reflexos na maior vastidão e complexidade dos programas eclesiásticos e na sobrecarga decorativa. Estas concessões verificam-se, sobretudo, no ocaso de Trezentos e aumentaram a partir do século seguinte, como deixam adivinhar os templos dos conventos de Guimarães, do Porto e de Évora, mais tardiamente construídos. Podemos ver nestas cedências um prenúncio das controvérsias posteriores, responsáveis por crises fraturantes e divisões dentro da Ordem com reflexos claros na espiritualidade e na arquitetura dos conventos.

\section{FONTES E BIBLIOGRAFIA}

\section{Crónicas}

Frei Jerónimo de Belém. 1750-1758. Chronica Serafica da santa Provincia dos Algarves, 4 vols. Lisboa.

Fr. Manuel da Esperança. 1666. Historia Seráfica da Ordem dos Frades Menores de S. Francisco na Provincia de Portugal, II parte, Lisboa, Ofic. de Antonio Craesbeeck de Mello

\section{Estudos}

Cuadrado Sanchez, Marta. 1991. "Arquitectura franciscana en España (siglos XIII y XIV)”, Archivo Ibero-Americano, 201-202, LI, p. 25.

Garcia Oro, José. 1988. "Francisco de Assis en la España medieval”, Liceo Franciscano, 121-123, p. 312.

Garcia Oro, José. 2005. "Los frailes menores en la hispania medieval. Proceso de Asentamiento", El Franciscanismo en la Península Ibérica. Balance y perspectivas, Actas do I Congresso Internacional AHEF, ed. Maria de Mar Graña Cid, Barcelona, G.B.G. Editora, pp. 201-209.

Jorge, Virgolino Ferreira. 2011. As igrejas medievais dos Franciscanos em Portugal. Sintese de caracterização tipomorfológica, Sep. "Boletim Cultural da Assembleia Distrital de Lisboa", s. 4, 96, $1^{\circ}$ t.

Le Goff, Jacques. 1968. "Apostolat mendiant et fait urbain dans la France médievale”, Annales. Économies, Sociétés, Civilisations, 23, 2, pp. 335-352. 
Macedo, Francisco Pato de. 2017. Santa Clara-a-Velha de Coimbra. Singular mosteiro mendicante, Casal de Cambra, Caleidoscópio, pp. 15-108.

Mattoso, José. 1985. "O enquadramento social e económico das primeiras fundações franciscanas”, Portugal medieval. Novas interpretaçōes, Lisboa, Imprensa Nacional -Casa da Moeda, pp. 329-345.

Moreira, António Montes. 1996. "Implantação e desenvolvimento da Ordem Franciscana em Portugal. Séculos XIII-XVI”, Actas I-II Seminário O Franciscanismo em Portugal Séculos XIII-XVI, Convento da Arrábida, 1994, Lisboa, Fundação do Oriente, pp. 13-27.

Moreira, António Montes. 2000. "Franciscanos. 1. Das origens à divisão da ordem (1217 -1517)", Dicionário de história religiosa de Portugal, dir. Carlos Moreira Azevedo, vol. 2, Lisboa, Circulo de Leitores, pp. 273-280.

Moorman, John. 1968. A History of the Franciscan Order from its Origins to the Year 1517, Chicago, Clarendon.

Pellegrini, Luigi. 1990. "Território e città nella dinamica insediativa degli Ordini Mendicanti in Campania”, Gi Ordini Mendicanti e la città. Aspetti architettonici, sociali e politici, ed. de Joselita Raspi Serra, Milano, Guerini, p. 30.

Serra, Joselita Raspi. 1990. "Gli Ordini Mendicanti e la cittá. Premessa”, Gli Ordini Mendicanti e la Città. Aspetti architettonici, sociali e politici, ed. de Joselita Raspi Serra, Milano, Guerini, p. 14.

Sousa, Bernardo Vasconcelos e (dir.). 2005. Ordens Religiosas em Portugal. Das origens a Trento. Guia Histórico, Lisboa, Livros Horizonte. 